\title{
Parental socioeconomic position and development of overweight in adolescence: longitudinal study of Danish adolescents
}

Camilla Schmidt Morgen ${ }^{1 *}$, Laust Hvas Mortensen², Mette Rasmussen ${ }^{3}$, Anne-Marie Nybo Andersen², Thorkild IA Sørensen ${ }^{4}$, Pernille Due ${ }^{3}$

\begin{abstract}
Background: An inverse social gradient in overweight among adolescents has been shown in developed countries, but few studies have examined whether weight gain and the development of overweight differs among adolescents from different socioeconomic groups in a longitudinal study. The objective was to identify the possible association between parental socioeconomic position, weight change and the risk of developing overweight among adolescents between the ages 15 to 21 .

Methods: Prospective cohort study conducted in Denmark with baseline examination in 1996 and follow-up questionnaire in 2003 with a mean follow-up time of 6.4 years. A sample of 1,656 adolescents participated in both baseline (mean age 14.8) and follow-up (mean age 21.3). Of these, 1,402 had a body mass index (BMI = weight/ height ${ }^{2} \mathrm{~kg} / \mathrm{m}^{2}$ ) corresponding to a value below 25 at baseline when adjusted for age and gender according to guidelines from International Obesity Taskforce, and were at risk of developing overweight during the study period. The exposure was parental occupational status. The main outcome measures were change in BMI and development of overweight (from BMI $<25$ to $\mathrm{BMI}>=25$ ).

Results: Average BMI increased from 21.3 to 22.7 for girls and from 20.6 to 23.6 in boys during follow-up. An inverse social gradient in overweight was seen for girls at baseline and follow-up and for boys at follow-up. In the full population there was a tendency to an inverse social gradient in the overall increase in BMl for girls, but not for boys. A total of $13.4 \%$ developed overweight during the follow-up period. Girls of lower parental socioeconomic position had a higher risk of developing overweight (OR's between 4.72; $\mathrm{Cl} 1.31$ to 17.04 and 2.03; Cl 1.10-3.74) when compared to girls of high parental socioeconomic position. A tendency for an inverse social gradient in the development of overweight for boys was seen, but it did not meet the significance criteria
\end{abstract}

Conclusions: The levels of overweight and obesity among adolescents are high and continue to rise. Results from this study suggest that the inverse social gradient in overweight becomes steeper for girls and emerges for boys in late adolescence (age span 15 to 21 years). Late adolescence seems to be an important window of opportunity in reducing the social inequality in overweight among Danish adolescents.

\section{Background}

The prevalence of overweight and obesity has increased markedly among children and adolescents in recent years in Denmark as it has internationally [1-7]. Although recent studies suggest that the rapid increase in childhood obesity prevalence may be leveling off

\footnotetext{
* Correspondence: csm@niph.dk

${ }^{1}$ Institute of Public Health, University of Copenhagen, Denmark

Full list of author information is available at the end of the article
}

[8-10], this does not seems to be the case among adolescents [9]. The teenage years may be important in the life course development of obesity, as obese adolescents often become obese adults [4,11-13] with elevated risk of hypertension, impaired vascular function, type 2 diabetes, systemic inflammation, oxidative stress and coronary heart disease $[14,15]$. Furthermore overweight and obesity in adolescence may themselves be a more powerful predictors of these risks regardless of 
overweight and obesity in adulthood [5,16,17]. Overweight adolescents may experience a reduction in the quality of life [18] because of lower self-esteem [19], discrimination [20], poorer body image [19] and poor social and economic outcomes in young adulthood $[12,21,22]$ associated with the early onset of obesity $[23,24]$.

In cross sectional studies, obesity has been shown to be related to socioeconomic position among children and adolescents as suggested by Sobal and Stunkard in 1989 [25] and by Shrewsbury and Wardle in 2008 [26]. The studies show that in developed countries children from low socioeconomic families appear to be at higher than average risk for overweight and obesity. The opposite gradient is seen in some middle-income countries. In these countries there are also examples of opposite gradients between boys and girls, with an inverse gradient for girls [27]. Ball et al. reviewed the literature on socioeconomic status and weight change among adults in 2005 showing a relatively consistent inverse relationship over time when socioeconomic status was measured as occupation [28]. However, few studies have explored if this is the case for children and adolescents [29-31], and it remains unknown at what age the relationship between socioeconomic position and obesity emerges [25] and whether it leads to a self-promoting vicious cycle in which the psychosocial adverse effects of obesity worsen the obesity [32].

A good understanding of when the inverse social gradient in overweight emerges, if this gradient is changeable and either strengthens or weakens as adolescents move into adulthood may provide useful insights for the development of an effective prevention strategy targeting socioeconomic inequality in overweight. Therefore, we aimed to investigate whether there is an inverse social gradient in overweight and weight change, and whether the inverse social gradient in overweight emerges or changes during late adolescence in a Danish setting.

\section{Methods}

\section{Sample}

The study comprised a sample of 23 municipalities selected to be representative of all municipalities in Denmark, supplemented by a representative sample of schools from the two largest cities in Denmark, Copenhagen and Aarhus. In the municipalities included (except for Aarhus and Copenhagen), the samples comprised all students who underwent the standard health examination by a school physician before leaving school in the school year 1996/97. The health examinations are offered to all schools and take place in both private and public schools.

The storage and linking of the data was approved by the Danish Data Protection Agency and The Danish

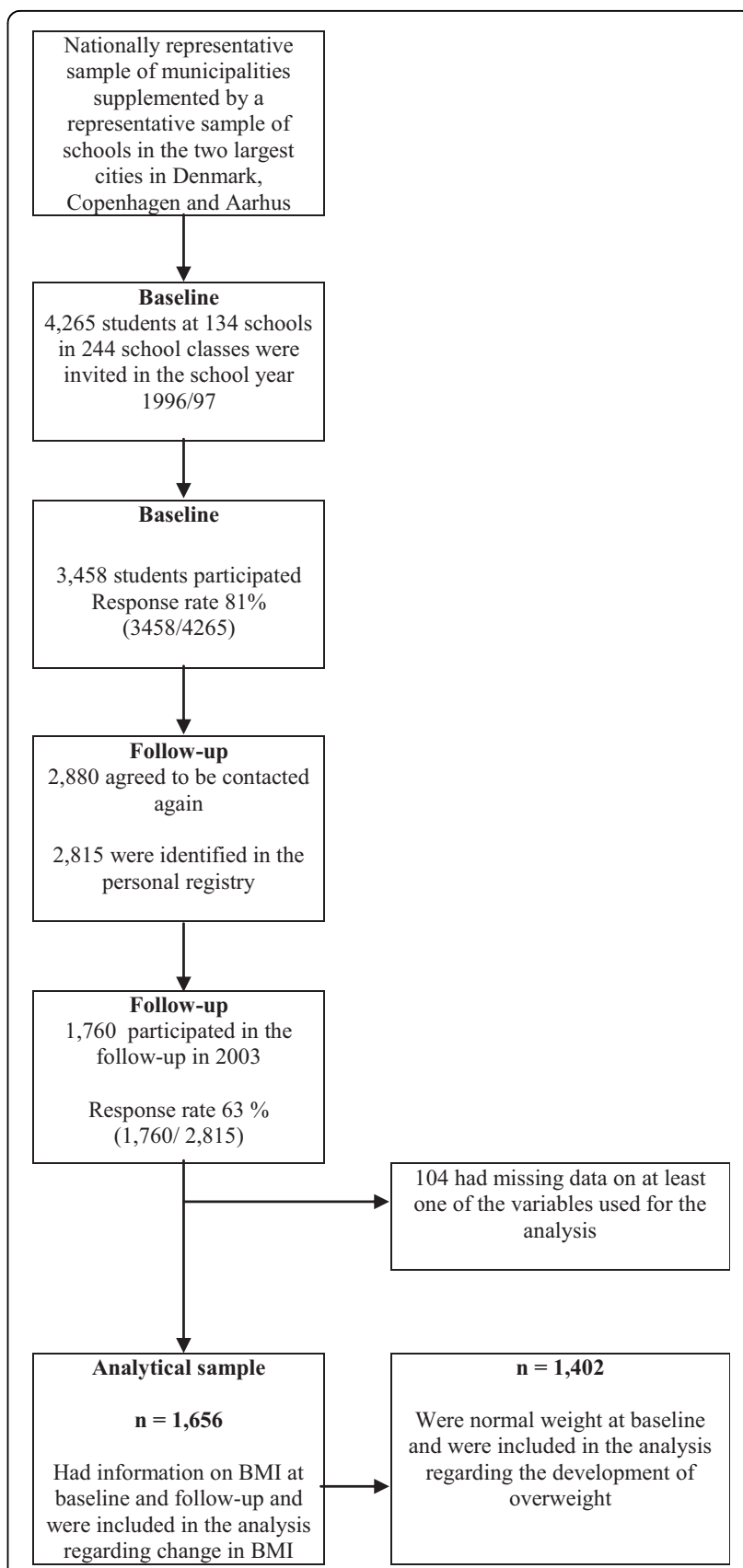

Figure 1 Flow chart showing the sampling in the study.

National Committee on Biomedical Research Ethics approved the collection of data.

As shown in figure 1, a total of 3,458 14-16-year-old students were enrolled in the cohort at baseline in 1996-97. They were all examined by a school physician, who measured height, weight and reported parents' socioeconomic position. Of those invited, 81 percent participated at baseline. A total of 2,880 agreed to be contacted again. 
At follow-up, we identified 2,815 of the 20-22-yearolds in the civil registry by their personal identification number (after permission from the National Board of Health and the Danish Data Protection Agency) and they were invited to participate. The follow-up consisted of a self-administered questionnaire, including selfreported height and weight. A total of 1,760 returned the questionnaire (response rate at 1,760/2,815 =63\%). In the analyses we excluded 104 with missing information on height and weight. Body Mass Index (BMI = weight $(\mathrm{kg}) /$ height $\left.^{2}(\mathrm{~m})\right)$ was calculated for each individual on the basis of measured weight and height at baseline and on the basis of self-reported weight and height at follow-up. Thus, 1,656 participants were eligible for analyses on change in BMI during follow-up, and 1,402 with a normal weight at baseline were eligible for the analysis regarding the development of overweight.

At baseline, girls and individuals with parents from the highest socioeconomic groups were overrepresented when compared to the Danish population in general.

\section{Exposure}

We used socioeconomic position measured by occupation of the parents as exposure. Information about parental socioeconomic position came from the school physician questionnaire and was reported at baseline. The school physician determined parental occupational status from own knowledge about the child, from information from the child and from the teacher. The ranking was based on DISCO-88 classification, which is a Danish version of ISCO-88 used by Statistics Denmark http://www.dst.dk. In order to combine information on paternal and maternal occupational level into one variable we used the highest level of occupational status from either the father or mother, whichever was higher. We worked with eight occupational groups and they were ranked with unemployed as the lowest level and self-employed as the highest level. We used white-collar group 1 as reference, since this group was more homogeneous and bigger than the group of self-employed.

The levels were defined as unemployed, non-skilled manual worker, under education, skilled-manual worker, white-collar group 3, white-collar group 2, white-collar group 1 and self-employed. The categorisation was made from a combination of four questions regarding occupation of the mother and father and a question regarding the reason for not being on the labour market for the mother and the father.

From the questionnaire we have aggregated self-employed with self-employed farmers into one. The group of selfemployed included self-employed with and without employees. The unemployed group contains disability retired, housewife (unemployed), unemployed, long time illness (unemployed) and people receiving social security benefit.

\section{Outcome}

There were two primary outcomes: increase in BMI and development of overweight $(\mathrm{BMI}>=25$, including obese) during the study period.

Change in BMI in the full population was categorised as a continuous measure of upward change in crude BMI "points" (not adjusted for age) from baseline to follow-up.

Since adult BMI criteria for overweight and obesity underestimate the proportion of overweight and obesity among adolescents we categorized the students' weight status using the International Obesity Task Force (IOTF) criteria, which identify BMI for each age in half years differentiated on sex with a predicted BMI of 25 or more at age 18 [33]. Students with an age and sex adjusted BMI [33] corresponding to a value below 25 at baseline were categorised as normal weight, and students with a BMI at or above $25(\mathrm{n}=254)$ were excluded from the analysis regarding the risk of developing overweight.

Adolescents with an age and sex adjusted BMI corresponding to a value below 25 at baseline and above or at 25 at follow-up were categorized as individuals becoming overweight during the study period.

\section{Statistical analysis}

In this study, students were nested within naturally occurring hierarchies of school physicians (students were examined by 34 different school physicians) and schools (pupils nested in 134 different schools). To account for the cluster sampling of the study, we used multilevel linear regression to examine the change in BMI from baseline to follow-up, adjusting for school physician and school cluster effects and multilevel logistic regression to examine the risk of developing overweight while adjusting for school physician and school cluster effects [34-36]. We did not adjust for school class cluster effects, as there were less than 10 students in all classes in the final analytical sample. We used STATA software version 10.0 and used the procedures XTMELOGIT and XTMIXED.

\section{Results}

\section{Adolescents lost to follow-up}

At baseline a total of 3,458 students were included in the study, as shown in table 1 . Of these, 1,802 were excluded from the final analytical sample because they were lost to follow-up or had missing information on key variables. The excluded group was not different from the included group $(n=1,656)$ regarding $B M I$ and age at baseline, but they had a higher prevalence of parents from lower socioeconomic groups, and a lower proportion of males and of individuals living with both biological parents. 
Table 1 Descriptive characteristics of the individuals included in the analytical sample $(n=1656)$ and those excluded because of loss to follow-up or missing information on key variables $(n=1802)$

\begin{tabular}{|c|c|c|c|c|c|}
\hline Characterstics & & $\begin{array}{l}\text { Included } \\
(\mathrm{n}=1656)\end{array}$ & $\begin{array}{l}\text { Excluded } \\
(\mathrm{n}=1802)\end{array}$ & $\begin{array}{l}\mathrm{n} \text { in the } \\
\text { excluded } \\
\text { group* }\end{array}$ & $\begin{array}{c}\text { p-value, } \\
\chi^{2 / t \text {-test }}\end{array}$ \\
\hline $\begin{array}{l}\text { Crude mean BMI at } \\
\text { baseline (std. dev) }\end{array}$ & & $21.0(3.0)$ & $20.9(3.1)$ & 1,663 & 0.53 \\
\hline \multirow{2}{*}{$\begin{array}{l}\text { Age adjusted BMI } \\
\text { according to IOTF } \\
\text { criteria[33] }\end{array}$} & $<25$ & $84.7 \%$ & $82.8 \%$ & 1,087 & 0.19 \\
\hline & $\geq 25$ & $15.3 \%$ & $17.2 \%$ & & \\
\hline
\end{tabular}

Age at baseline

$\begin{array}{lcc}13 & 0.6 \%(10) & 0.4 \%(7) \\ 14 & 24.5 \%(405) & 22.3 \%(401) \\ 15 & 69.0 \%(1143) & 69.4 \%(1248) \\ 16 & 5.7 \%(95) & 7.5 \%(135) \\ 17 & 0.1 \%(2) & 0.4 \%(7) \\ 18 & 0.1 \%(1) & 0.1 \%(1)\end{array}$

Sex

\begin{tabular}{|c|c|c|c|}
\hline Male & $38.1 \%(631)$ & $54.5 \%(982)$ & 1,802 \\
\hline Female & $61.9 \%(1025)$ & $45.5 \%(820)$ & \\
\hline
\end{tabular}

Lives with

\begin{tabular}{|c|c|c|c|c|c|}
\hline & Biological parents & $75.2 \%(1246)$ & $67.9 \%(1186)$ & & \\
\hline & One biological, one cohabitant & $11.0 \%(182)$ & $14.4 \%(251)$ & 1,748 & $<0.0001$ \\
\hline & One parent & $12.2 \%(202)$ & $15.2 \%(265)$ & & \\
\hline & Other than parents & $0.7 \%(12)$ & $1.6 \%(28)$ & & \\
\hline & Not known & $0.9 \%(14)$ & $1.0 \%(18)$ & & \\
\hline \multirow{8}{*}{$\begin{array}{l}\text { Socioeconomic } \\
\text { position, } \\
\text { highest of the parents }\end{array}$} & Unemployed & $5.7 \%(94)$ & $11.8 \%(212)$ & & \\
\hline & Non-skilled manual worker & $7.6 \%(125)$ & $10.2 \%(184)$ & 1,802 & $<0.0001$ \\
\hline & Under education & $1.3 \%(21)$ & $2.3 \%(42)$ & & \\
\hline & Skilled manual worker & $9.5 \%(157)$ & $10.0 \%(181)$ & & \\
\hline & White-collar group 3 & $19.1 \%(317)$ & $18.8 \%(338)$ & & \\
\hline & White-collar group 2 & $26.2 \%(433)$ & $20.9 \%(377)$ & & \\
\hline & White-collar group 1 & $18.7 \%(309)$ & $13.4 \%(242)$ & & \\
\hline & Self-employed & $12.1 \%(200)$ & $12.5 \%(226)$ & & \\
\hline Total & & $100 \%$ & $100 \%$ & & \\
\hline
\end{tabular}

*Numbers vary according to the number of students with missing information

Mean BMI, prevalence of overweight and obesity

Table 2 shows the rise in mean crude BMI from 21.3 to 22.7 (mean rise 1.4 (95\% CI: 1.3;1.6) p < 0.0001) for girls and from 20.6 to 23.6 (mean rise 3.0 (95\% $\mathrm{CI}: 2.8 ; 3.2), \mathrm{p}<0.0001)$ for boys during the follow-up period. A total of $15.5 \%(159 / 1,025)$ of the girls and
$15.1 \%(95 / 631)$ of the boys were overweight (BMI $\geq 25$, including obese), when measured at baseline. At follow up the percentages for overweight (obese included) based on self-reported weight and height were 19.5 $(200 / 1,025)$ and $24.4(154 / 631)$ for girls and boys respectively. A total of $3.0 \%(31 / 1,025)$ of the girls and $1.6 \%$ 
Table 2 Socioeconomic and anthropometric characteristics of the study population by $\operatorname{sex}(n=1,656)$

\begin{tabular}{|c|c|c|c|}
\hline Baseline characteristics, 1996-97 & Girls, $n=1,025$ & Boys, $n=631$ & $\mathrm{p}$-value, $\chi 2 / \mathrm{t}$-test \\
\hline Mean age $\left(S D^{*}\right)$ & $14.8(0.5)$ & $14.8(0.6)$ & \\
\hline Average weight $(\mathrm{SD})$ & 58.4 kg (9.7 kg) & 62.7 kg (10.8kg) & $<0.0001$ \\
\hline Mean height (SD) & $165.7 \mathrm{~cm}(6.1 \mathrm{~cm})$ & $174.2 \mathrm{~cm}(7.6 \mathrm{~cm})$ & \\
\hline Crude mean BMI (SD) (weight in kg/(height in meters $\left.{ }^{2}\right)$ ) & $21.3(3.2)$ & $20.6(2.7)$ & $<0.0001$ \\
\hline \multicolumn{4}{|l|}{ Age adjusted BMI according to IOTF criteria** } \\
\hline$<25$ & $84.5 \%(866)$ & $84.9 \%(536)$ & 0.16 \\
\hline $25 \leq \mathrm{BMl}<30$ & $12.4 \%(127)$ & $13.5 \%(85)$ & \\
\hline$\geq 30$ & $3.0 \%(31)$ & $1.6 \%(10)$ & \\
\hline \multicolumn{4}{|l|}{ Socioeconomic position, highest of the household } \\
\hline Unemployed & $5.9 \%(60)$ & $5.4 \%(34)$ & 0.73 \\
\hline Non-skilled manual worker & $7.7 \%(79)$ & $7.3 \%(46)$ & \\
\hline Under education & $1.5 \%(15)$ & $1.0 \%(6)$ & \\
\hline Skilled manual worker & $9.9 \%(101)$ & $8.9 \%(56)$ & \\
\hline White-collar group 3 & $19.9 \%(204)$ & $17.9 \%(113)$ & \\
\hline White-collar group 2 & $26.1 \%(267)$ & $26.3 \%(166)$ & \\
\hline White-collar group 1 & $17.7 \%(181)$ & $20.3 \%(128)$ & \\
\hline Self-employed & $11.5 \%(118)$ & $13.0 \%(82)$ & \\
\hline Total & $100 \% 1025$ & $100 \% 631$ & \\
\hline
\end{tabular}

\begin{tabular}{|c|c|c|c|}
\hline Follow-up characteristics, 2003 & Girls, $n=1,025$ & Boys, $\mathrm{n}=631$ & \\
\hline Mean age (SD) & $21.2(0.7)$ & $21.3(0.7)$ & \\
\hline Average weight (SD) & $64.8 \mathrm{~kg}(11.0 \mathrm{~kg})$ & 78.7 kg (11.5 kg) & $<0.0001$ \\
\hline Mean height (SD) & $169.0 \mathrm{~cm}(6.2 \mathrm{~cm})$ & $182.6 \mathrm{~cm}(6.7 \mathrm{~cm})$ & $<0.0001$ \\
\hline Crude mean BMI (SD) (weight in kg/(height in meters $\left.{ }^{2}\right)$ ) & $22.7(3.6)^{* * *}$ & $23.6(3.0)^{* * *}$ & $<0.0001$ \\
\hline \multicolumn{4}{|l|}{ BMI cut points } \\
\hline$<25$ & $80.5 \%(825)$ & $75.6 \%(477)$ & 0.02 \\
\hline $25 \leq \mathrm{BMl}<30$ & $15.1 \%(155)$ & $20.4 \%(129)$ & \\
\hline$\geq 30$ & $4.4 \%(45)$ & $4.0 \%(25)$ & \\
\hline \multicolumn{4}{|l|}{ Individuals becoming overweight at follow-up** } \\
\hline Yes, moved from $\mathrm{BMI}<25$ to $\mathrm{BMI} \geq 25$ & $11.2 \%(97)$ & $17.0 \%(91)$ & 0.002 \\
\hline No & $88.8 \%(769)$ & $83.0 \%(445)$ & \\
\hline \multicolumn{4}{|l|}{ Individuals becoming normal weight at follow-up } \\
\hline Yes, moved from $\mathrm{BMI} \geq 25^{*}$ to $\mathrm{BMI}<25$ & $35.2 \%(56)$ & $33.7 \%(32)$ & 0.80 \\
\hline No & $64.8 \%(103)$ & $66.3 \%(63)$ & \\
\hline
\end{tabular}

*Standard deviation

**BMI cut points at baseline according to IOTF criteria[33]

***Difference from baseline crude mean BMI $p<0.0001$. 
$(10 / 631)$ of the boys were obese $(\mathrm{BMI} \geq 30)$ at baseline. At follow-up the percentages for obesity were 4.4 (45/ $1,025)$ and $4.0(25 / 631)$ for girls and boys respectively.

\section{Weight development during the six-year study period}

As shown in the lower part of table 2, a total of $11.2 \%$ (97/866) of the non-overweight girls (BMI corresponding to an age and sex adjusted value below 25) at baseline developed overweight over the six-year study period. 17.0\% (91/536) of the non-overweight boys developed overweight during the study period.

A total of $35.2 \%$ (56/159) of girls who were overweight at baseline moved to a normal weight over the six years, and $33.7 \%$ (32/95) of the overweight boys moved from overweight to normal weight in the study period. The percentages moving to a normal weight range were larger for individuals from families of higher socioeconomic position (data not shown).

\section{The inverse social gradient in overweight at baseline and follow-up}

Results from multilevel logistic regression analysis, shown in table 3, revealed an inverse social gradient in overweight at baseline and at follow-up among girls. Girls from families with an occupational level corresponding to white-collar group 1 had the lowest risk of overweight at baseline and at follow-up. Girls from families with an occupational level corresponding to unemployed, non-skilled manual worker, under education, skilled manual worker, white-collar group 3 to 1 and self-employed had increased risks of overweight, both at baseline and at follow-up when compared to girls from white-collar group 1 families. Though the confidence intervals were wide, the inverse social gradient in overweight seemed steeper at follow-up, indicating that the relative social inequality in overweight was more pronounced among the population of 21-year-old girls than in the population of 15 -year-old girls. The two gradients are, however, not calculated in the same number of subjects (1544 versus 1025 included) as we wanted to keep as many individuals as possible in the baseline sample in order to show a social gradient as close as possible to the one in the source population.

For boys the overall p-value indicated that parental occupational status was associated with overweight at baseline. Based on the OR estimates, however, there seemed to be no clear inverse social gradient in overweight among boys at baseline. At follow-up, based on the OR estimates, an inverse social gradient in overweight was present. Boys from families with a parental occupational level corresponding to non-skilled manual worker, skilled manual worker and white-collar group 3 had a higher risk of overweight when compared to boys from families with a parental occupational level corresponding to white-collar group 1. An inverse social gradient in overweight seemed to emerge in late adolescence for boys. Again, due to attrition, the gradients are measured in two different populations (1199 versus 631 boys included).

Adjusting for school physician and school effects did not alter the results.

\section{Association between socioeconomic position and change in BMI from baseline to follow-up in the entire study population}

Table 4 shows that parental socioeconomic position had an influence on the overall weight change from baseline to follow-up for females, but not for males. The $\beta$ coefficient indicates the change in BMI from baseline to follow-up relative to the reference group, white-collar group 1. Adjusting for school and school physician cluster effects did not alter the results.

\section{Association between socioeconomic position and the development of overweight}

An inverse social gradient was seen in the development of overweight in girls, as shown in table 5. Compared to girls with a parental occupational level corresponding to white-collar group 1, girls in families with an occupational level of white-collar group 2, white-collar group 3, under education and non-skilled manual workers had a significantly higher risk of developing overweight over the six-year study period, between the ages 15 to 21 years. Girls with parents in the unemployed and selfemployed groups did not have a higher risk of developing overweight than girls with parents in white-collar group 1.

For boys there was no significant social gradient in the risk of developing overweight in the six-year study period between the mean ages of 15 to 21 years.

Due to the sample size it was not possible to adjust for school physician cluster effects. Adjusting for school cluster effects did not alter the results.

\section{Discussion}

Based on a sample of 1,656 adolescents, we found high rates of overweight and obesity combined at around $15.5 \%$ at the age of 15 years and the proportion increased markedly to $19.5 \%$ and $24.4 \%$ for girls and boys, respectively, from the age of 15 to 21 years. Parental socioeconomic position was associated with the overall rise in BMI from the age of 15 to 21 among girls only. An inverse social gradient was seen in the development of overweight among girls. A tendency for an inverse social gradient in the development of overweight for boys was seen, but it did not meet the significance criteria, possibly due to lack of statistical power because more boys than girls were lost to follow-up. Overweight 
Table 3 Multilevel logistic regression analysis (OR, $95 \% \mathrm{CI})$ of the cross-sectional associations between parental socioeconomic position and overweight at baseline $(n=2743)^{*}$ and at follow-up $(n=1656)$

\begin{tabular}{|c|c|c|c|c|c|c|}
\hline Socioeconomic position & $\mathrm{N}$ & $\%$ & $\%$ overweight & OR ** & $95 \% \mathrm{Cl}$ & p-value $* * *$ \\
\hline Baseline, female & 1544 & 100 & & & & $<0.000$ \\
\hline Unemployed & 107 & 6.9 & 13.3 & 1.88 & $1.11 ; 321$ & \\
\hline Non-skilled manual worker & 144 & 9.3 & 20.3 & 3.28 & $2.10 ; 5.11$ & \\
\hline Under education & 29 & 1.9 & 20.0 & 2.36 & $1.07 ; 5.18$ & \\
\hline Skilled manual worker & 155 & 10.0 & 16.8 & 1.41 & $0.87 ; 2.28$ & \\
\hline White-collar group 3 & 308 & 20.0 & 15.7 & 1.95 & $1.30 ; 2.90$ & \\
\hline White-collar group 2 & 372 & 24.1 & 13.1 & 1.51 & $1.02 ; 2.24$ & \\
\hline White-collar group $1 /$ ref.group & 235 & 15.2 & 10.5 & 1.00 & & \\
\hline Self-employed & 194 & 12.6 & 24.6 & 3.63 & $2.38 ; 5.51$ & \\
\hline Baseline, male & 1199 & 100 & & & & $<0.0001$ \\
\hline Unemployed & 82 & 6.8 & 36.5 & 0.87 & $0.48 ; 1.57$ & \\
\hline Non-skilled manual worker & 107 & 8.9 & 21.7 & 0.94 & $0.57 ; 1.53$ & \\
\hline Under education & 17 & 1.4 & 0.0 & 0.23 & $0.05 ; 1.04$ & \\
\hline Skilled manual worker & 103 & 8.6 & 21.4 & 0.97 & $0.59 ; 1.60$ & \\
\hline White-collar group 3 & 226 & 18.9 & 23.9 & 1.31 & $0.89 ; 1.93$ & \\
\hline White-collar group 2 & 295 & 24.6 & 6.0 & 0.53 & $0.35 ; 0.80$ & \\
\hline White-collar group $1 /$ ref.group & 207 & 17.3 & 12.5 & 1.00 & & \\
\hline Self-employed & 162 & 13.5 & 13.4 & 1.1 & $0.68 ; 1.62$ & \\
\hline Follow-up, female & 1025 & 100 & & & & $<0.000$ \\
\hline Unemployed & 60 & 5.9 & 13.3 & 1.40 & $0.69 ; 2.86$ & \\
\hline Non-skilled manual worker & 79 & 7.7 & 34.2 & 5.30 & $3.11 ; 9.02$ & \\
\hline Under education & 15 & 1.5 & 28.7 & 4.75 & $1.80 ; 12.54$ & \\
\hline Skilled manual worker & 101 & 9.9 & 26.7 & 3.81 & $2.30 ; 6.34$ & \\
\hline White-collar group 3 & 204 & 19.9 & 19.6 & 2.47 & $1.56 ; 3.93$ & \\
\hline White-collar group 2 & 267 & 26.1 & 19.1 & 2.38 & $1.52 ; 3.71$ & \\
\hline White-collar group $1 /$ ref.group & 181 & 17.7 & 8.8 & 1.00 & - & \\
\hline Self-employed & 118 & 11.5 & 21.2 & 2.49 & $1.49 ; 4.17$ & \\
\hline Follow-up, male & 631 & 100 & & & & 0.005 \\
\hline Unemployed & 34 & 5.4 & 26.5 & 1.94 & $0.78 ; 4.79$ & \\
\hline Non-skilled manual worker & 46 & 7.3 & 34.8 & 2.82 & $1.28 ; 6.23$ & \\
\hline Under education**** & 6 & 1.0 & 0.0 & - & - & \\
\hline Skilled manual worker & 56 & 8.9 & 32.1 & 2.55 & $1.22 ; 5.34$ & \\
\hline White-collar group 3 & 113 & 17.9 & 35.4 & 2.93 & $1.58 ; 5.44$ & \\
\hline White-collar group 2 & 166 & 26.3 & 19.3 & 1.28 & $0.69 ; 2.37$ & \\
\hline White-collar group $1 /$ ref.group & 128 & 20.3 & 15.6 & 1.00 & & \\
\hline Self-employed & 82 & 13.0 & 23.2 & 1.60 & $0.78 ; 3.27$ & \\
\hline
\end{tabular}

*The number varies from the baseline population at $n=3458$ because of missing information on BMI at baseline.

${ }^{*}$ Adjusted for school physician and school cluster effects.

***P-value for a Likelihood Ratio test of the overall effect of socioeconomic position on overweight.

****No events in this category, excluded from the analysis. 
Table 4 Multilevel linear regression analysis ( $\beta$-values, $95 \% \mathrm{Cl}$ ) of the association between parental socioeconomic position and overall change in BMI from baseline in 1996 to follow-up in 2003 by gender ( $n=$ 1656).

\begin{tabular}{|c|c|c|c|c|c|}
\hline $\begin{array}{l}\text { Socioeconomic position } \\
\text { (highest of the parents) }\end{array}$ & $\mathrm{n}$ & $\%$ & $\begin{array}{c}\text { Multilevel } \\
\text { analysis, } \\
\text { two } \\
\text { level } \\
\text { model } \\
\beta^{*}\end{array}$ & $\begin{array}{c}\mathrm{p}- \\
\text { value }\end{array}$ & $95 \% \mathrm{Cl}$ \\
\hline Female & 1025 & & & 0.007 & \\
\hline Unemployed & 60 & 9 & -0.54 & & $\begin{array}{c}-1.29 \\
0.21\end{array}$ \\
\hline Under education & 79 & 9 & 0.55 & & $\begin{array}{l}-0.13 \\
1.23\end{array}$ \\
\hline Non-skilled manual worker & 15 & 2 & 0.70 & & $\begin{array}{l}-0.66 \\
2.05\end{array}$ \\
\hline Skilled manual worker & 101 & 9 & 1.04 & & $\begin{array}{l}0.42 ; \\
1.67\end{array}$ \\
\hline White-collar group 3 & 204 & 19 & 0.19 & & $\begin{array}{l}-0.33 \\
0.70\end{array}$ \\
\hline White-collar group 2 & 267 & 24 & 0.21 & & $\begin{array}{l}-0.28 \\
0.69\end{array}$ \\
\hline $\begin{array}{l}\text { White-collar group 1/ref. } \\
\text { group }\end{array}$ & 181 & 17 & 0.00 & & - \\
\hline Self-employed & 118 & 13 & -0.02 & & $\begin{array}{l}-0.61 \\
0.58\end{array}$ \\
\hline Male & 631 & & & 0.94 & \\
\hline Unemployed & 150 & 8 & -0.14 & & $\begin{array}{l}-0.10 \\
0.73\end{array}$ \\
\hline Non-skilled manual worker & 168 & 9 & 0.39 & & $\begin{array}{l}-0.39 \\
1.17\end{array}$ \\
\hline Under education & 38 & 2 & -0.42 & & $\begin{array}{l}-2.31 \\
1.47\end{array}$ \\
\hline Skilled manual worker & 182 & 10 & 0.14 & & $\begin{array}{l}-0.58 \\
0.87\end{array}$ \\
\hline White-collar group 3 & 343 & 19 & 0.23 & & $\begin{array}{l}-0.36 \\
0.81\end{array}$ \\
\hline White-collar group 2 & 412 & 23 & 0.10 & & $\begin{array}{l}-0.43 \\
0.63\end{array}$ \\
\hline $\begin{array}{l}\text { White-collar group 1/ref. } \\
\text { group }\end{array}$ & 270 & 15 & 0.00 & & - \\
\hline Self-employed & 218 & 12 & -0.05 & & $\begin{array}{c}-0.69 \\
0.59\end{array}$ \\
\hline
\end{tabular}

${ }^{*}$ Adjusted for school physician and school cluster effects.

**P-value for a Likelihood Ratio test of the overall effect of socioeconomic position on overweight.

was associated with parental occupational status for girls at the age of 15 and for both sexes at the age of 21. The gradient emerged for boys and increased for girls during the six years of follow-up.

Adolescence may be a critical period for the development of overweight, as overweight may persist through adult life [4,11,37-39] - resulting in many years of elevated risk of morbidity and mortality.

As seen in previous studies [1,5-7,27], our findings show high rates of overweight in adolescence and the rates increase further into young adulthood.

We found a cross sectional inverse social gradient in overweight at the ages 15 and 21 for girls and at age 21 for boys. The social gradient in overweight among adolescents has been addressed by Sobal and Stunkard in their review from 1989 [25], where the authors did not find evidence of a distinct social pattern in obesity in developed countries. The authors did though find a remarkably strong inverse relationship between socioeconomic status and obesity among women $[25,40]$. In a more recent review by Wardle et al from 2008 the authors concluded that the most prominent pattern was an inverse social gradient in adiposity among adolescents in Western societies [26]. A comparative study on socioeconomic position, macro-economic environment, and overweight among adolescents in 35 countries found that the direction and magnitude of social inequality in adolescent overweight showed large international variation, with inverse social gradients in most Western European countries, but positive social gradients, especially for boys, in some Central European countries [27], supporting the findings of cross-sectional socioeconomic gradients in overweight in this study.

It has not previously been well documented whether weight gain and development of overweight in adolescence is socially patterned or when this pattern emerges. We found that the risk of developing overweight in late adolescence was significantly higher among girls from families with lower socioeconomic positions and that the relative gradient increased for girls in this age span, but this was not statistically significant for boys. The lack of association for boys could be explained by a big loss to follow-up, but as the cross-sectional inverse social gradient is increased for girls, we cannot preclude that the gradient only persists for girls in this age span.

The transition from puberty to adulthood could be particularly challenging for young women, for whom an attractive body image may be of greater importance than for the young men. Being of lower social class origin may make a transition with this expectation more difficult for women than for men, and hence the likelihood of development of obesity may be greater in these women than in men from the same classes [27].

In the review on childhood predictors of adult obesity by Parsons et al from 1999, the authors found no evidence of an association between socioeconomic status in early life and childhood obesity [41]. Though not directly comparable, results from a longitudinal Canadian study provide evidence that effects of neighbourhood disadvantage on children's BMI occur between 
Table 5 Multilevel logistic regression analysis (OR, $95 \% \mathrm{Cl}$ ) of the association between parental socioeconomic position and the risk of developing overweight between age 15 and 21 years among non-overweight individuals $(\mathrm{n}=$ 1402)

\begin{tabular}{|c|c|c|c|c|c|}
\hline Socioeconomic position (highest of the parents) & n & $\%$ & OR & p-value & $95 \% \mathrm{Cl}$ \\
\hline Female & 866 & & & 0.020 & \\
\hline Unemployed & 52 & 6.0 & 1.00 & & $0.36 ; 2.81$ \\
\hline Non-skilled man. worker & 63 & 7.3 & 4.08 & & $2.03 ; 8.22$ \\
\hline Under education & 12 & 1.4 & 4.72 & & $1.31 ; 17.04$ \\
\hline Skilled manual worker & 84 & 9.7 & 3.48 & & $1.80 ; 6.75$ \\
\hline White-collar group 3 & 172 & 19.9 & 2.03 & & $1.10 ; 3.74$ \\
\hline White-collar group 2 & 232 & 26.8 & 2.70 & & $1.52 ; 4.79$ \\
\hline White-collar group 1/ref.group & 162 & 18.7 & 1.00 & & - \\
\hline Self-employed & 89 & 10.3 & 1.12 & & $0.51 ; 2.47$ \\
\hline Male & 536 & & & 0.067 & \\
\hline Unemployed & 25 & 4.7 & 0.60 & & $0.16 ; 2.22$ \\
\hline Non-skilled man. worker & 36 & 6.7 & 1.23 & & $0.54 ; 2.80$ \\
\hline Under education & 6 & 1.1 & - & & - \\
\hline Skilled manual worker & 44 & 8.2 & 1.79 & & $0.85 ; 3.78$ \\
\hline White-collar group 3 & 86 & 16.0 & 1.87 & & $1.00 ; 3.52$ \\
\hline White-collar group 2 & 156 & 29.1 & 1.13 & & $0.63 ; 2.03$ \\
\hline White-collar group 1/ref.group & 112 & 20.9 & 1.00 & & - \\
\hline Self-employed & 71 & 13.3 & 1.05 & & $0.53 ; 2.10$ \\
\hline
\end{tabular}

*Adjusted for school cluster effects.

**No events in this group, excluded from the analysis.

childhood and early adolescence and in a five-year longitudinal study based on an English population of adolescents Wardle et al. found that the inverse social gradient in overweight was already established at the age of 11 and that no further divergence occurred from the age of 11 [29]. These results are not in line with the findings of this study, where the inverse social gradient in overweight changed and got steeper from 15 to 21 years, which may indicate differences between developed countries. Alternatively, it could be explained by the use of different measures of socioeconomic position. Oliver et al. used neighbourhood income and Wardle et al. used residential area as a proxy for the socioeconomic position of the adolescents. Our findings are supported by a recent study by Sherwood et al. based on an American population of adolescents in which girls from families of lower socioeconomic position were at increased risk of developing overweight. No association was seen among boys. Socioeconomic position was primarily measured by parental education and, in addition, occupation and eligibility for public assistance [30].

\section{Strengths and limitations}

This study is based on a nationally representative sample of adolescents, which increases the external validity.
Information regarding height and weight at baseline was measured objectively, while at follow-up they were self reported. The main weakness of the study is the large attrition, which may bias the results. Participants who did not attend follow-up, were more often from families with lower socioeconomic position, and were less often living with both biological parents, all factors contributing to the risk of selection bias. Since more boys than girls were lost to follow-up, we might have underestimated the social inequality in the development of overweight among boys. These results should therefore be interpreted with caution. However, as the group lost to follow-up did not differ with regards to BMI at baseline, and since the participation rate in the school physician examinations (at baseline) is generally high, we believe that the associations found are not severely biased due to loss to follow-up.

Another limitation of the study is the self-reported measurements of height and weight at follow-up, since self-reporting tends to lead to an underreporting of BMI at follow-up [42,43]. This potential misclassification might lead to an underestimation of the number of participants who develop overweight and an overestimation of the number of participants who achieve a healthy weight range during the six-year study period. Two 
previous studies have found misclassification to be larger among adolescents from lower socioeconomic groups $[44,45]$, which would mean that associations in our study are underestimated. A false association between parental occupational status and the longitudinal development of overweight would appear if participants from families with a lower socioeconomic position at baseline were more likely to under- or over report weight at follow-up. We have not been able to find research covering this subject.

The use of BMI as a measure of weight status has been criticised because it is not sex-specific for adults and may be confounded by skeletal structure [46]. More precise measures such as waist circumference and DEXA scans were not available and BMI was suitable at follow-up to secure the least degree of non-response. BMI is though a widely used and accepted measure in epidemiological studies.

The use of parental occupational status as the exposure had limitations as the information from the questionnaire was difficult to aggregate into fewer socioeconomic groups. A further aggregation of the categories would have made the interpretation unclear and would have thrown away too much of the information given in the questionnaires.

A further limitation of the exposure used is the fact that the source of information was the school physician, who determined parental occupational status from its own knowledge about the child, from information from the child and from the school teacher. How thorough school physicians were in obtaining this information may have differed. We have, though, considered this possible bias to be non-differential as we find it most likely that the proportion of misclassified individuals does not depend on the later risk of obesity.

Parental occupational status is one of many ways to quantify the socioeconomic position of adolescents and it seems to have an influence on weight gain and risk of obesity that is independent of the parents' own degree of obesity [47]. Information on parental educational and income levels might improve the understanding of the factors and processes that create the socioeconomic disparities in overweight and the development of overweight among adolescents.

\section{Conclusions}

The levels of overweight and obesity among adolescents are high and continue to rise. In our study, the results suggest that the inverse social gradient in overweight gets steeper for girls and arises for boys in late adolescence. Late adolescence seems to be an important window of opportunity in reducing the social inequality in overweight among Danish adolescents.

\section{Acknowledgements}

This study was supported by grants from The Danish Ministry of Health

\section{Author details}

${ }^{1}$ Institute of Public Health, University of Copenhagen, Denmark. ${ }^{2}$ Department of Social Medicine, University of Copenhagen, Copenhagen K, Denmark. ${ }^{3}$ National Institute of Public Health, University of Southern Denmark.

${ }^{4}$ Institute of Preventive Medicine, Copenhagen University Hospital, Copenhagen, Denmark.

\section{Authors' contributions}

The CSM, ANA and PDU author designed and initiated the study. CSM and LHM author performed the statistical analyses. All authors helped gather or interpret data and write the article. All authors approved the final version of the article. The study complies with the Helsinki declaration on ethics in science. There are no conflicting interests regarding the funding of the study. The storage and linking of the data were approved by the Danish Data Protection Agency, and The Danish National Committee on Biomedical Research Ethics approved the collection of data.

\section{Competing interests}

The authors declare that they have no competing interests.

Received: 3 February 2010 Accepted: 29 August 2010

Published: 29 August 2010

\section{References}

1. Due P, Heitmann BL, Sorensen TIA: Prevalence of obesity in Denmark. Obesity Reviews 2007, 8:187-189.

2. Lissau I, Overpeck MD, Ruan WJ, Due P, Holstein BE, Hediger ML: Body mass index and overweight in adolescents in 13 European countries, Israel, and the United States. Arch Pediatr Adolesc Med 2004, 158:27-33.

3. Reilly JJ, Armstrong J, Dorosty AR, Emmett PM, Ness A, Rogers I, et al: Early life risk factors for obesity in childhood: cohort study. BMJ 2005, 330:1357.

4. Whitaker RC, Wright JA, Pepe MS, Seidel KD, Dietz WH: Predicting obesity in young adulthood from childhood and parental obesity. $N$ Engl J Med 1997, 337:869-873

5. Lobstein T, Baur L, Uauy R: Obesity in children and young people: a crisis in public health. Obes Rev 2004, 5(Suppl 1):4-104

6. Ogden $\mathrm{CL}$, Flegal $\mathrm{KM}$, Carroll MD, Johnson $\mathrm{CL}$ : Prevalence and trends in overweight among US children and adolescents, 1999-2000. JamaJournal of the American Medical Association 2002, 288:1728-1732.

7. Matthiessen J, Groth MV, Fagt S, Biltoft-Jensen A, Stockmarr A, Andersen JS, et al: Prevalence and trends in overweight and obesity among children and adolescents in Denmark. Scandinavian Journal of Public Health 2008, 36:153-160.

8. Han JC, Lawlor DA, Kimm SYS: Childhood obesity. Lancet 2010, 375:1737-1748.

9. Pearson S, Hansen B, Sorensen TI, Baker JL: Overweight and obesity trends in Copenhagen schoolchildren from 2002 to 2007. Acta Paediatr 2010.

10. Lissner L, Sohlstrom A, Sundblom E, Sjoberg A: Trends in overweight and obesity in Swedish schoolchildren 1999-2005: has the epidemic reached a plateau? Obes Rev 2009.

11. Dietz WH: Critical periods in childhood for the development of obesity. Am J Clin Nutr 1994, 59:955-959.

12. Freedman DS, Dietz WH, Srinivasan SR, Berenson GS: The relation of overweight to cardiovascular risk factors among children and adolescents: the Bogalusa Heart Study. Pediatrics 1999, 103:1175-1182.

13. Sorensen TI, Sonne-Holm S: Risk in childhood of development of severe adult obesity: retrospective, population-based case-cohort study. Am J Epidemiol 1988, 127:104-113.

14. Burke V: Obesity in childhood and cardiovascular risk. Clin Exp Pharmacol Physiol 2006, 33:831-837.

15. Baker $\mathrm{L}$, Olsen LW, Sorensen TI: Childhood body-mass index and the risk of coronary heart disease in adulthood. N Engl J Med 2007, 357:2329-2337.

16. Must A, Jacques PF, Dallal GE, Bajema CJ, Dietz WH: Long-term morbidity and mortality of overweight adolescents. A follow-up of the Harvard Growth Study of 1922 to 1935. N Engl J Med 1992, 327:1350-1355. 
17. Power C, Lake JK, Cole TJ: Measurement and long-term health risks of child and adolescent fatness. International Journal of Obesity 1997, 21:507-526.

18. Swallen KC, Reither EN, Haas SA, Meier AM: Overweight, obesity, and health-related quality of life among adolescents: The national longitudinal study of adolescent health. Pediatrics 2005, 115:340-347

19. Wardle J, Waller J, Fox E: Age of onset and body dissatisfaction in obesity. Addictive Behaviors 2002, 27:561-573.

20. Puhl RM, Andreyeva T, Brownell KD: Perceptions of weight discrimination: prevalence and comparison to race and gender discrimination in America. International Journal of Obesity 2008, 32:992-1000.

21. Gortmaker SL, Must A, Perrin JM, Sobol AM, Dietz WH: Social and economic consequences of overweight in adolescence and young adulthood. N Engl J Med 1993, 329:1008-1012.

22. Sobal J: Social and Economic Consequences of Overweight in Adolescence. New England Journal of Medicine 1994, 330:647.

23. Sorensen TI, Sonne-Holm S: Intelligence test performance in obesity in relation to educational attainment and parental social class. J Biosoc $\mathrm{SCl}$ 1985, 17:379-387.

24. Sonne-Holm S, Sorensen TI: Prospective study of attainment of social class of severely obese subjects in relation to parental social class, intelligence, and education. Br Med J (Clin Res Ed) 1986, 292:586-589.

25. Sobal J, Stunkard AJ: Socioeconomic-Status and Obesity - A Review of the Literature. Psychological Bulletin 1989, 105:260-275.

26. Shrewsbury $V$, Wardle J: Socioeconomic status and adiposity in childhood: A systematic review of cross-sectional studies 1990-2005. Obesity 2008, 16:275-284

27. Due P, Damsgaard MT, Rasmussen M, Holstein BE, Wardle J, Merlo J, et al: Socioeconomic position, macroeconomic environment and overweight among adolescents in 35 countries. International Journal of Obesity 2009, 33:1084-1093.

28. Ball K, Crawford D: Socioeconomic status and weight change in adults: a review. Social Science \& Medicine 2005, 60:1987-2010

29. Wardle J, Brodersen NH, Cole TJ, Jarvis MJ, Boniface R: Development of adiposity in adolescence: five year longitudinal study of an ethnically and socioeconomically diverse sample of young people in Britain. British Medical Journal 2006, 332:1130-1132A.

30. Sherwood NE, Wall M, Neumark-Sztainer D, Story M: Effect of socioeconomic status on weight change patterns in adolescents. Prev Chronic Dis 2009, 6:A19.

31. Oliver LN, Hayes MV: Effects of neighbourhood income on reported body mass index: an eight year longitudinal study of Canadian children. BmC Public Health 2008, 8.

32. Stunkard AJ, Sorensen Tl: Obesity and socioeconomic status-a complex relation. N Engl J Med 1993, 329:1036-1037.

33. Cole TJ, Bellizzi MC, Flegal KM, Dietz WH: Establishing a standard definition for child overweight and obesity worldwide: international survey. BMJ 2000, 320:1240-1243.

34. Larsen K, Merlo J: Appropriate assessment of neighborhood effects on individual health: Integrating random and fixed effects in multilevel logistic regression. American Journal of Epidemiology 2005, 161:81-88.

35. Ohlsson H, Merlo J: Understanding the effects of a decentralized budget on physicians' compliance with guidelines for statin prescription - a multilevel methodological approach. Bmc Health Services Research 2007, 7.

36. Rabe-Hesketh S, Skrondal A: Multilevel and Longitudinal Modeling Using Stata Texas: Stata Press, Second 2008

37. Dietz WH: Overweight in childhood and adolesence. New England Journal of Medicine 2004, 350:855-857.

38. Freedman DS, Khan LK, Serdula MK, Dietz WH, Srinivasan SR, Berenson GS The relation of childhood BMI to adult adiposity: The Bogalusa Heart Study. Pediatrics 2005, 115:22-27.

39. Sonneholm S, Sorensen TIA, Jensen G, Schnohr P: Long-Term Changes of Body-Weight in Adult Obese and Nonobese Men. International Journal of Obesity 1990, 14:319-326.

40. Sorensen TI: Socio-economic aspects of obesity: causes or effects? Int J Obes Relat Metab Disord 1995, 19(Suppl 6):S6-S8.

41. Parsons TJ, Power C, Logan S, Summerbell CD: Childhood predictors of adult obesity: a systematic review. Int J Obes Relat Metab Disord 1999, 23(Suppl 8):S1-107.
42. Elgar FJ, Roberts C, Tudor-Smith C, Moore L: Validity of self-reported height and weight and predictors of bias in adolescents. Journal of Adolescent Health 2005, 37:371-375.

43. Goodman E, Hinden BR, Khandelwal S: Accuracy of teen and parental reports of obesity and body mass index. Pediatrics 2000, 106:52-58.

44. Himes JH, Hannan P, Wall M, Neumark-Sztainer D: Factors associated with errors in self-reports of stature, weight, and body mass index in Minnesota adolescents. Annals of Epidemiology 2005, 15:272-278.

45. Jansen W, Looij-Jansen PMV, Ferreira I, de Wilde EJ, Brug J: Differences in measured and self-reported height and weight in Dutch adolescents. Annals of Nutrition and Metabolism 2006, 50:339-346.

46. Taylor RW, Jones IE, Williams SM, Goulding A: Evaluation of waist circumference, waist-to-hip ratio, and the conicity index as screening tools for high trunk fat mass, as measured by dual-energy X-ray absorptiometry, in children aged 3-19 y. American Journal of Clinical Nutrition 2000, 72:490-495.

47. Teasdale TW, Sorensen TIA, Stunkard AJ: Genetic and Early Environmental Components in Sociodemographic Influences on Adult Body Fatness. British Medical Journal 1990, 300:1615-1618.

\section{Pre-publication history}

The pre-publication history for this paper can be accessed here:

http://www.biomedcentral.com/1471-2458/10/520/prepub

doi:10.1186/1471-2458-10-520

Cite this article as: Morgen et al: Parental socioeconomic position and development of overweight in adolescence: longitudinal study of Danish adolescents. BMC Public Health 2010 10:520.

\section{Submit your next manuscript to BioMed Central and take full advantage of:}

- Convenient online submission

- Thorough peer review

- No space constraints or color figure charges

- Immediate publication on acceptance

- Inclusion in PubMed, CAS, Scopus and Google Scholar

- Research which is freely available for redistribution

Submit your manuscript at www.biomedcentral.com/submit
Biomed Central 